with caffeine and have had no other complications. All 20 infants had EEGs performed before treatment with caffeine and 13 of these infants had EEGs performed while being treated with caffeine. No abnormalities have been observed. The mechanisms involved in the 'unmasking' may be due to the stimulatory effect of caffeine on the CNS with lowering of the seizure threshold.

\section{References}

1 Kelly DH, Shannon DC. Treatment of apnea and excessive periodic breathing in the full term infant. Pediatrics 1981; 68:183-6.

2 Ritchie JM. Central nervous system stimulants: the xanthines. In: Goodman LS, Gilman A, eds. The pharmacologic basis of therapeutics. 5th ed. London: MacMillan, 1975:367.

3 Kelly DH, Shannon DC. Sudden infant death syndrome and near miss sudden infant death syndrome: a review of the literature 1964-1982. Pediatric Clinics NA 1982;29:1241-61.

${ }^{4}$ Kelly DH, Shannon DC, O'Connell K. Care of infants with near-miss sudden infant death syndrome. Pediatrics 1978;61:511-4.

5 Hunt CE, Brouillette RT, Hanson D. Theophylline improves pneumogram abnormalities in infants at risk for sudden infant death syndrome. J Pediatr 1983;103:969-74.

6 Aranda JV, Turmen T, Davis J, et al. Effect of caffeine on control of breathing in infantile apnea. $J$ Pediatr 1963; 103:975-8.

7 Aranda JV, Cook CE, Gorman W, et al. Pharmacokenetic profile of caffeine in the premature newborn infant with apnea. J Pediatr 1979;94:663-8.

Correspondence to Dr J V Aranda, Montreal Children's Hospital, 2300 Tupper Avenue, Montreal, Quebec H3H 1P3, Canada.

Received 27 February 1986

\title{
Neuroleptic malignant syndrome
}

\author{
A MOORE, N V O'DONOHOE, AND H MONAGHAN
}

Our Lady's Hospital for Sick Children, Dublin, Ireland

SUMMARY A case of the neuroleptic malignant syndrome, an idiosyncratic response to neuroleptic drugs, is described. Symptoms persisted for eight weeks. The stopping of neuroleptics and general supportive measures are the mainstay of treatment. Failure to recognise this syndrome can lead to morbidity and death.

The neuroleptic malignant syndrome is the most serious yet least known complication of neuroleptic therapy, characterised by muscular rigidity, hyperthermia, altered consciousness, and autonomic dysfunction. It was first described in $1960^{1}$ and up to 1984 over 80 cases had been reported, mainly in adult, medical, and psychiatric spheres. We report a case of the neuroleptic malignant syndrome occurring in childhood.

\section{Case report}

The case was an 8 year old boy, who had presented at the age of 10 months with microcephaly and mental handicap considered to be due to maternal treatment with phenytoin during pregnancy. He had attended a special school and was not being treated with drugs but had been given thioridazine in 1979 for nine days. There was no family history of anaesthetic problems. He had had a febrile illness before admission and had been prescribed $5 \mathrm{mg}$ prochlorperazine six hourly because of vomiting. After three days of treatment he had sudden onset of extreme agitation, opisthotonos, and episodic dystonic movements. This persisted and he was admitted to hospital.

On admission he had a fever of $38^{\circ} \mathrm{C}$ and was dehydrated. His remarkable posture and involuntary movements were unabated (Figure), yet he was able to recognise his parents. Except for transient benefit from sedation he remained in this state for the following eight weeks, also showing widespread evidence of autonomic dysfunction - that is, periodic rises of temperature to $40^{\circ} \mathrm{C}$, profuse diaphoresis, apex rate 100 to 140 per minute, respiratory rate 45 to 50 beats per minute, and blood pressure $90 / 50$ to $120 / 70$. Investigations showed a white blood cell count of 13000 and normal result of blood count, tests on cerebrospinal fluid, viral studies, electroencephalography, and computed tomography. He had raised liver and muscle enzymes: aspartate aminotransferase 662 (normal 8-40) iu/l, alanine aminotransferase 226 (normal 5-35) $\mathrm{iu} / \mathrm{l}$, and creatine phosphokinase 5243 (normal 0-130) iu/l. Initially, this was thought to be a prolonged drug induced dystonia, but the condition was unresponsive to the usual therapeutic regimens. It was noteworthy that the only drug that seemed to be of benefit in sedating the patient was thioridazine, itself a phenothiazine. After an interval of 


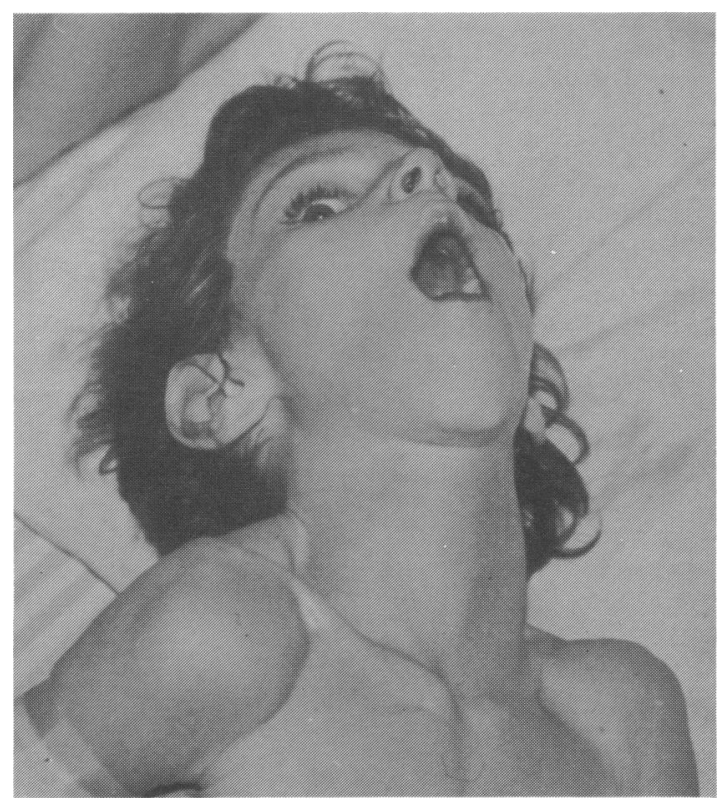

Figure Abnormal posture in a case of neuroleptic malignant syndrome.

roughly four weeks a diagnosis of neuroleptic malignant syndrome was made and his various treatments were stopped. Within hours he showed pronounced clinical deterioration to a state of extreme opisthotonos. Treatment with thioridazine, benzhexol, and levadopa was resumed and, after gradual increases in levadopa up to a total dose of $625 \mathrm{mg}$ daily, he showed steady improvement and eventually he reverted to his premorbid state. Treatment with drugs was stopped 12 weeks after admission and no further relapse occurred.

\section{Discussion}

The neuroleptic malignant syndrome classically occurs after treatment with neuroleptic drugs, also known as 'major' tranquilisers, such as the phenothiazines, butyrophenones, and thioxanthenes. ${ }^{2} 3$ Characteristic features have also been described after the use of neuroleptics in combination with lithium and in sedative-hypnotic withdrawal states, as well as after the use of monoamine oxidase inhibitor-tricyclic antidepressant combinations. ${ }^{2}$ It is an idiosyncratic response, occurring after therapeutic rather than toxic doses of the drug, and is unrelated to the duration of treatment, though depot preparations are often implicated. ${ }^{3}$ All ages and both sexes are affected in the neuroleptic malignant syndrome, but young adult males predominate among reported cases. The disorder is usually more striking in psychiatric patients, in those with organic brain disease (as in our patient), and in a setting of dehydration or physical exhaustion. Neuroleptic malignant syndrome typically develops over a period of 24-72 hours. The symptoms persist for five to 10 days and two to three times longer when associated with depot forms of the drug. In our case symptoms persisted for eight weeks.

The syndrome begins with severe extrapyramidal symptoms of rigidity and akinesia together with or shortly before the development of fever and autonomic disturbance. The autonomic disturbances consist of hyperpyrexia, excessive perspiration, tachycardia, dyspnoea, dysuria, urinary incontinence, and labile or sustained hypertension. Involuntary movements, such as tremor, chorea, and oculogyric crisis, may also occur. Hypertonic involvement of pharyngeal muscles often results in dysarthria, dysphasia, and sialorrhoea. Consciousness fluctuates from alert mutism to stupor and coma. Respiratory failure is the commonest cause of death. There is an overall mortality of $20 \%$, which is higher for depot than for oral neuroleptics. ${ }^{2}$ Neurological function usually returns to the previous baseline, although four cases of irreversible brain damage after combined treatment with haloperidol and lithium have been reported. ${ }^{4}$

There are no specific or diagnostic laboratory findings in neuroleptic malignant syndrome but leucocytosis, raised creatine kinase activity, and abnormal liver function values have been reported. ${ }^{3}$ The electroencephalogram is generally normal but may show non-specific slow wave activity. Cerebrospinal fluid, isotope brain scans, computed tomograms, and postmortem examination usually show no abnormality.

The pathogenesis of the neuroleptic malignant syndrome is not clear, but excessive dopamine receptor blockade in the basal ganglia, causing extrapyramidal symptoms, and in the hypothalamus, where dopamine receptors are concerned in thermoregulation and other autonomic functions, has been postulated. ${ }^{3}$ The differential diagnosis includes infectious, vascular, neoplastic, and traumatic disorders affecting the central nervous system, phenothiazine related heat stroke, malignant hyperthermia, and idiopathic acute lethal catatonia.

Treatment consists of prompt recognition of the syndrome, withdrawal of the offending drug, and general supportive care. Reports of treatment with anticholinergic drugs and dopaminergic drugs have been made but no concensus has been reached. Dantrolene, a drug used in relieving rigidity in 
malignant hyperthermia, may offer an effective treatment. ${ }^{56}$

\footnotetext{
References

${ }^{1}$ Delay J, Pichot P, Lemperiere T, Elissalde B, Perigre F. Un neuroleptique majeur non phenothiazin que et non reserpinque l'haloperidol dans le traitment dès psychoses. Ann Med Psychol (Paris) 1960;118:145-52.

2 Caroff SN. The neuroleptic malignant syndrome. J Clin Psychiatry 1980;41:79-83.

${ }^{3}$ Smego RA, Duralk DT. The neuroleptic malignant syndrome. Arch Intern Med 1982;142:1183-5.
}

${ }^{4}$ Cohen WJ, Cohen NH. Lithium carbonate, haloperidol and irreversible brain damage. JAMA 1974;230:1283-7.

${ }^{5}$ Coons DJ, Hillman FJ, Marshall RW. Treatment of neuroleptic malignant syndrome with dantrolene sodium. A case report. Am J Psychiatry 1982:139:944-5.

${ }^{6}$ Goulon M, De Rohan Chabot P, Elkharrat D, et al. Beneficial effects of dantrolene in the treatment of neuroleptic malignant syndrome. A report of two cases. Neurology (NY) 1983;33: 516-8.

Correspondence to Dr H Monaghan, Our Lady's Hospital for Sick Children, Crumlin, Dublin 12, Ireland.

Received 24 March 1986

\title{
Oral administration of active vitamin D metabolites to low birthweight infants
}

\author{
I Z KOVAR, P D MAYNE, J J JAMES, AND I C BARNES \\ Departments of Child Health and Chemical Pathology, Charing Cross and Westminster Medical School, \\ London
}

SUMmarY The active vitamin D metabolites $1 \alpha, 25-$ dihydroxycholecalciferol (Rocaltrol) and the analogue $1 \alpha$-hydroxycholecalciferol (One-Alpha) are adequately absorbed after oral administration in the preterm infant. The absorption pattern is similar to that seen in adults.

Bone demineralisation is common in low birthweight preterm infants, with a reported incidence of up to $32 \%$. Vitamin D metabolites are prescribed in the management and prophylaxis of early onset hypocalcaemia and rickets. ${ }^{12}$ There is little information available on the absorption and acute metabolic effect after oral administration of these metabolites to preterm infants. We report on 10 low birthweight preterm infants who received an equivalent oral dose of 1 $\alpha, 25$-dihydroxycholecalciferol (Rocaltrol, Roche Products, Herts, United Kingdom) or $1 \alpha$-hydroxycholecalciferol (One-Alpha, Leo Laboratories, Bucks, UK).

\section{Patients and methods}

Two groups of five infants (two boys and three girls each) were studied. Group 1 , who had a median gestational age of 28 weeks (range 27-29 weeks) and birth weight of $1210 \mathrm{~g}$ (range 840-1360 g), received $0.1 \mu \mathrm{g} / \mathrm{kg}$ of One-Alpha at a median postnatal age of 4 weeks (range 3-5). Group 2, who had a median gestational age of 28 weeks (range 27-30 weeks) and birth weight of $1110 \mathrm{~g}$ (range $870-1200 \mathrm{~g}$ ), received $0.1 \mu \mathrm{g} / \mathrm{kg}$ of Rocaltrol at a median postnatal age of 4 weeks (range 3-5 weeks).

Both agents were prepared according to the manufacturer's protocol and given as a single morning oral dose. At the time of investigation the feeding regimens in both groups were identical; two infants in both were receiving expressed breast milk, two mixed feed, expressed breast milk, and standard formula feed, and one standard formula feed alone. No infant had clinical, biochemical, or radiological evidence of bone demineralisation or of hypocalcaemia.

Blood $(1.5 \mathrm{ml})$ was collected by venepuncture immediately predose and at six and 24 hours postdose. It was not considered ethically correct to take additional samples at other times. The first postdose sample time of six hours was chosen to approximate to the peak absorbed concentration time as based on available data from adults. ${ }^{3}$

Blood was separated within half an hour of collection and the plasma aliquoted and stored frozen at $-20^{\circ} \mathrm{C}$ till assayed. Plasma 25-hydroxycholecalciferol and 1 $\alpha, 25$-dihydroxycholecalciferol concentrations were assayed in duplicate by competitive protein binding after sephadex column separation by the method of Mallon et al. ${ }^{4}$ Individual patient samples were analysed within the same assay batch. The interassay coefficient of variation for 25 -hydroxycholecalciferol was $11 \%$ while for $1 \alpha, 25$-dihydroxycholecalciferol it was $12 \%$. Plasma calcium concentration was assayed by a manual 